\title{
Direct reconstruction of np elastic scattering amplitudes between 0.80 and $1.1 \mathrm{GeV}$
}

J. Ball $\left({ }^{1}\right)$, J. Bystricky $\left({ }^{2}\right)$, J.-M. Fontaine $\left({ }^{1}\right)$, G. Gaillard $\left({ }^{3}\right)$, R. Hess $\left({ }^{3}\right) \dagger$

Z. Janout $\left({ }^{1}\right)\left({ }^{4}\right)$, B. A. Khachatlrov $\left({ }^{5}\right)$, R. KunNe $\left({ }^{1}\right)\left({ }^{3}\right)$, C. D. LaC $\left({ }^{1}\right)\left({ }^{2}\right)$

C. Lechanoine-Leluc $\left({ }^{3}\right)$, F. Lehar $\left({ }^{2}\right)$, A. De Lesquen $\left({ }^{2}\right)$, D. Lopiano $\left({ }^{6}\right)$

F. Perrot-Kunne $\left({ }^{2}\right)$, D. Rapin $\left({ }^{3}\right)$, L. van Rossum $\left({ }^{2}\right)$

H. SCHMitT $\left({ }^{7}\right)$ and H. M. SPINKA $\left({ }^{6}\right)$

(') Laboratoire National SATURNE, CNRS/IN2P3 and CEAIDSM, CE Saclay F-91191 Gif sur Yvette Cedex, France

(2) CEA-DAPNIA/SPP, CE Saclay - F-91191 Gif-sur-Yvette Cedex, France

( $\left.{ }^{3}\right)$ DPNC, University of Geneva-24, quai Ermest-Ansermet, $\mathrm{CH}-1211$ Geneva 4, Switzerland

( $\left.{ }^{4}\right)$ Faculty of Nuclear Sciences and Physical Engineering, Czech Technical University Břehová 7, CZ-11519 Prague 1, Czech Republic

(5) Laboratory of Nuclear Problems, IINR - 141980 Dubna, Moscow Region, Russia

(6) HEP Division, Argonne National Labonatory - 9700 South Cass Avenue, Argonne, IL 60439, USA

(') Fakultät für Physik der Freiburg Universität - D.79104 Freiburg, Germany

(ricevuto il 20 Agosto 1997; revisionato il 16 Gennaio 1998; approvato l'11 Marzo 1998)

Summary. - The direct reconstruction of the neutron-proton elastic-scattering amplitudes was carried out at six energies from 0.80 to $1.1 \mathrm{GeV}$. At the five highest energies the complete sets of spin-dependent observables used were measured in the nucleon-nucleon experimental program at SATURNE II. At $0.80 \mathrm{GeV}$, LAMPF data were also used. The invariant amplitudes $a, b, c, d$, and $e$ were fit to the experimental data using a least-squares method. A search for solutions starting from random initial values was performed to determine different possible sets of amplitudes. The real and imaginary parts at several angles are listed in tables and compared with the predictions of two phase shift analyses.

PACS 13.75.Cs - Nucleon-nucleon interactions (including antinucleons, deuterons, etc.)

\section{1. - Introduction}

Puzikov, Ryndin and Smorodinskii [1] introduced the concept of "complete experiment" for the case of nucleon-nucleon (NN) scattering. They proposed a certain

The submitted manuscript has been created by the University of Chicago as Operator of Argonne National Laboratory ("Argonne") under Contract No. W-31-109-ENG-38 with the U.S. Department of Energy. The U.S. Government retains for itself, and others act. ing on its behalt, a paid-up. nonexclusive, irrevocable worldwide license in said article to reproduce, prepare derivative works, distribute copies to the public, and perform pub. licly and display publicly, by or on behalf of the Government. $\dagger$ Deceased.

(C) Società Italiana di Fisica 
ensemble of observables to be measured, which they called complete, if it contains sufficient information for an exhaustive description of the interaction. It has since then been established [2] that 10 appropriately chosen observables, including the differential cross-section, could already form a complete set, from which a direct reconstruction of the scattering matrix elements can be performed in a unique way, without any theoretical input, except the symmetry properties. Numerically, however, several solutions may be found even for a complete set of observables, since the data points are measured with errors.

Complete sets of observables in np elastic scattering, consisting of eleven different spin-dependent observables [3-9] were measured at $0.84,0.88,0.94,1.00$ and $1.10 \mathrm{GeV}$ using the SATURNE II polarized neutron beam and the Saclay frozen-spin polarized target. The $n p$ differential cross-sections, which provide an absolute normalization to all amplitudes (see eqs. (2.4)-(2.18)), were obtained from fit to all existing data [10]. At $0.80 \mathrm{GeV}$ a direct amplitude reconstruction was performed using the Saclay data at this energy, together with published LAMPF results [11-19] at $0.788 \mathrm{GeV}$.

The search for solutions was performed by a least-squares method starting from random sets of amplitudes. Some of the solutions could be removed by different criteria discussed below. The selected ones are listed and plotted in figures. They are compared with the predictions of the pp and np energy-dependent phase shift analysis (PSA) of the Virginia Polytechnic Institute (VPI) of ref.[10] and with the results of the Saclay-Geneva PSA at fixed energies [20], where pp and np data were introduced. The present amplitude analysis is the first direct reconstruction of the $n p$ scattering matrix.

The status of the pp amplitude reconstruction is described in ref. [21]. Before 1975, the direct reconstruction of pp scattering amplitudes was only possible for pp elastic scattering at $90^{\circ} \mathrm{c} . \mathrm{m}$. at a few energies [22]. The first direct reconstruction of the pp scattering matrix below $0.6 \mathrm{GeV}$ over a large angular region was carried out from the measurements at PSI and was reported in refs. [23-26]. A similar reconstruction has been performed on LAMPF data at $0.73 \mathrm{GeV}$ (ref. [27]). The reconstructions were carried out on PSI data at $0.59 \mathrm{GeV}$ and LAMPF data at $0.80 \mathrm{GeV}$ in ref. [28]. At higher energy, the SATURNE II data allowed reconstructions at 11 energies between 0.83 and $2.7 \mathrm{GeV}[29]$. At $6 \mathrm{GeV} / \mathrm{c}$ the amplitude analysis was performed using the ANL-ZGS data [30].

In contrast to the pp elastic-scattering amplitudes, the np ones are very poorly known at present. Nowadays only the SATURNE II data make this reconstruction possible at five energies and several angles between 0.84 and $1.10 \mathrm{GeV}$. The first preliminary results were presented in 1990 [31] and then in [32]. It is expected that the amplitude analysis below $0.6 \mathrm{GeV}$ with the PSI data [33] will be carried out soon.

Note that the revised summary of all measured SATURNE II np data is given in ref. [9]. These data are also available in the database of the University of Durham [34].

In sect. 2, the nucleon-nucleon formalism necessary for the amplitude analysis is described. The complementarity of the PSA and the amplitude analysis is discussed in sect. 3. Section 4 treats the data base and selection rules for amplitude analysis solutions. The amplitude analysis and PSA methods are compared. Results are presented and discussed in sect. 5 .

2. - Sc;

We conserv principl

where : directior

The : recoil, b the polit oriented analyze: along th The : Ignoring

Since th different scatterin observab We deno particle. 
it contilins $\therefore$ since then lurling the ch a direct inique way, Iy, however. ice the data

en different nd $1.10 \mathrm{GeV}$ in polarized nalization to clata [10]. At data at this

tarting from rent criteria re compared sis (PSA) of sults of the roduced. The p scattering

Before 1975, or pp elastic on of the $p p$ out from the struction has uctions were 3]. At higher between 0.83 d using the

- very poorly econstruction V. The first reted that the it soon.

til is given in niversity of

le analysis is $\therefore$ discussed in itude analysis Results are

\section{2. - Scattering matrix and observables}

We determine the complex scattering amplitudes $a, b, c, d$, and $e$, assuming parity conservation, time reversal invariance and isospin invariance (generalized Pauli principle) throughout. We use the scattering matrix in the form [35]:

$$
\begin{aligned}
M\left(\vec{k}_{f}, \vec{k}_{1}\right)=\frac{1}{2}\left[(a+b)+(a-b)\left(\vec{\sigma}_{1}, \vec{n}\right)\left(\vec{\sigma}_{2}, \vec{n}\right)+(c+d)\left(\vec{\sigma}_{1}, \vec{m}\right)\left(\vec{\sigma}_{2}, \vec{m}\right)+\right. & \\
& \left.+(c-d)\left(\vec{\sigma}_{1}, \vec{l}\right)\left(\vec{\sigma}_{2}, \vec{l}\right)+e\left(\vec{\sigma}_{1}+\vec{\sigma}_{2}, \vec{n}\right)\right]
\end{aligned}
$$

where $\vec{\sigma}_{1}$ and $\vec{\sigma}_{2}$ are the Pauli $2 \times 2$ matrices, $\vec{k}_{i}$ and $\vec{k}_{f}$ are the unit vectors in the direction of the incident and scattered particles, respectively, and

$$
\vec{n}=\frac{\left[\vec{k}_{i} \times \vec{k}_{f}\right]}{\left|\left[\vec{k}_{i} \times \vec{k}_{f}\right]\right|}, \quad \vec{m}=\frac{\vec{k}_{f}-\vec{k}_{i}}{\left|\vec{k}_{f}-\vec{k}_{i}\right|}, \quad \vec{l}=\frac{\vec{k}_{f}+\vec{k}_{i}}{\left|\vec{k}_{f}+\vec{k}_{i}\right|} .
$$

The subscripts of an observable $X_{\text {srbt }}$ refer to the polarization states of the scattered, recoil, beam and target particles, respectively. For the so-called "pure experiments", the polarizations of the incident and target particles in the laboratory system are oriented along the basis unit vectors $\vec{k}, \vec{n}, \vec{s}=[\vec{n} \times \vec{k}]$. The recoil protons were analyzed in the directions $\vec{k}^{\prime \prime}, \vec{n}, \overrightarrow{s^{\prime \prime}}=\left[\vec{n} \times \vec{k}^{\prime \prime}\right]$, where the unit vector $\vec{k}^{\prime \prime}$ is oriented along the direction of the recoil particle momentum.

The np scattering matrix contains the isosinglet $\left(M_{0}\right)$ and isotriplet $\left(M_{1}\right)$ matrices. Ignoring the electromagnetic interactions, the following relation is valid:

$$
M(\mathrm{np} \rightarrow \mathrm{np})=\frac{1}{2}\left(M_{0}+M_{1}\right)
$$

Since the symmetry properties following from the generalized Pauli principle are different for the isosinglet and isotriplet parts, no symmetry relations for np elastic scattering amplitudes with respect to $90^{\circ} \mathrm{c} . \mathrm{m}$. exist at all. We express the contributing observables [35] in terms of the scattering amplitudes $a, b, c, d$, and $e$ from eq. (2.1). We denote by $\theta$ the c.m. scattering angle and by $\theta_{2}$ the laboratory angle of the recoil particle.

$$
\sigma=\frac{\mathrm{d} \sigma}{\mathrm{d} \Omega}=\frac{1}{2}\left[|a|^{2}+|b|^{2}+|c|^{2}+|d|^{2}+|e|^{2}\right]
$$$$
\sigma A_{m m n}=\frac{1}{2}\left[|a|^{2}-|b|^{2}-|c|^{2}+|d|^{2}+|e|^{2}\right]
$$$$
\sigma D_{o n a m}=\frac{1}{2}\left[|a|^{2}+|b|^{2}-|c|^{2}-|d|^{2}+|e|^{2}\right]
$$

(2.) $\sigma K_{(m m s}=\frac{1}{2}\left[|a|^{2}-|b|^{2}+|c|^{2}-|d|^{2}+|e|^{2}\right]$ 


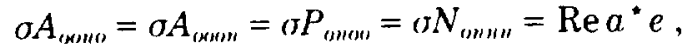

$$
\begin{aligned}
& \sigma A_{\text {rxws }}=+\operatorname{Re} a^{*} d \cos \theta-\operatorname{Im} d^{*} e \sin \theta+\operatorname{Re} b^{*} c, \\
& \sigma A_{\text {oxkk }}=-\operatorname{Re} a^{*} d \cos \theta+\operatorname{Im} d^{*} c \sin \theta+\operatorname{Re} b^{*} c, \\
& \text { (2.11) } \sigma A_{o o s k}=-\operatorname{Re} a^{*} d \sin \theta-\operatorname{Im} d^{*} e \cos \theta \text {, } \\
& \text { (2.12) } \sigma D_{0 *^{*} \circ k}=+\operatorname{Re} a^{*} b \sin \left(\theta+\theta_{2}\right)-\operatorname{Re} c^{*} d \sin \theta_{2}+\operatorname{Im} b^{*} e \cos \left(\theta+\theta_{2}\right) \text {, } \\
& \sigma K_{o s^{*} s o}=-\operatorname{Re} a^{*} c \cos \left(\theta+\theta_{2}\right)-\operatorname{Re} b^{*} d \cos \theta_{2}+\operatorname{Im} c^{*} e \sin \left(\theta+\theta_{2}\right), \\
& \text { (2.14) } \sigma K_{o s " k o}=+\operatorname{Re} a^{*} c \sin \left(\theta+\theta_{2}\right)-\operatorname{Re} b^{*} d \sin \theta_{2}+\operatorname{Im} c^{*} e \cos \left(\theta+\theta_{2}\right) \text {, } \\
& \text { (2.15) } \sigma K_{o k^{*}{ }_{s o}}=-\operatorname{Re} a^{*} c \sin \left(\theta+\theta_{2}\right)-\operatorname{Re} b^{*} d \sin \theta_{2}-\operatorname{Im} c^{*} e \cos \left(\theta+\theta_{2}\right) \text {, } \\
& \text { (2.16) } \sigma K_{o k^{* k o}}=-\operatorname{Re} a^{*} c \cos \left(\theta+\theta_{2}\right)+\operatorname{Re} b^{*} d \cos \theta_{2}+\operatorname{Im} c^{*} e \sin \left(\theta+\theta_{2}\right) \text {, } \\
& \text { (2.17) } \sigma N_{\text {onsh }}=-\operatorname{Re} d^{*} e \sin \theta+\operatorname{Im} a^{*} d \cos \theta+\operatorname{Im} b^{*} c \text {, } \\
& \text { (2.18) } \sigma N_{o n k k}=+\operatorname{Re} d^{*} e \cos \theta+\operatorname{Im} a^{*} d \sin \theta \text {. }
\end{aligned}
$$

Each observable is multiplied by the differential cross section, which is the unique absolute quantity $(\mathrm{mb} / \mathrm{sr})$. It plays the role of the normalization factor for all spindependent observables together. The observables are bilinear combinations of real and imaginary parts of amplitudes $(\sqrt{\mathrm{mb} / \mathrm{sr}})$, where each term contains a product of one direct and one complex conjugate parameter. One can express any amplitude $A$ by its absolute value and phase: $A=|A| \exp \left[i \phi_{A}\right]$. An addition of $\pm 360^{\circ}$ provides no effect and may be applied to each amplitude separately. Any other rotation of the amplitude system must be applied to all amplitudes together. It changes any real and imaginary part of the individual amplitudes, but their absolute values remain unaffected. The bilinear terms in expressions for each observable are thus invariant with respect to the rotation of the entire system. Consequently, one common phase is arbitrary and cancels in any observable relation at $\theta \neq 0^{\circ}, 180^{\circ}$. In the present paper we put

$$
e=\operatorname{Re} e=|e| \geqslant 0, \quad \operatorname{Im} e=0, \quad \phi_{c}=0 .
$$

All phases are then relative to $\phi_{c}$, and only 9 parameters are calculated in the amplitude analysis.

The use of $n p$ and pp amplitudes allows, in principle, to determine the amplitudes for the isospin state $I=0$. The simple relation for the two isospin contributions of eq. (2.3) may be used directly in the forward and backward directions and at $90^{\circ}$ (c.m.) only. At any other scattering angle, a common phase between the $p p$ and $n p$ systems must be determined. This question will be treated in a dedicated paper.

\section{3. - PSA and amplitude analysis complementarity}

In the following we discuss the complementarity of the amplitude analysis and PSA method, their relative advantages and limits. We stress the necessity of a check of PSA results by a direct reconstruction of the scattering matrix, if an amplitude analysis is possible. 
The amplitude analysis is performed at one energy and one angle, where it requires a complete set of measured observables. For this reason it is always limited to a small number of angles and it will never be a universal tool predicting unknown quantities. The information provided by an accurately measured angular dependence of observables is lost, or may be used only indirectly to eliminate some solutions. On the other hand, the amplitude analysis is completely model independent. It gives a pure phenomenological description of a given interaction channel without any additional conditions and has no energy limit. Since the solution at one angle is independent of those at other angles, the amplitude analysis can determine a possible anomaly in angular or energy dependences.

In the PSA approach the reconstruction of scattering amplitudes is possible even from incomplete sets of experimental quantities [36]. The $\theta_{\text {c.m. }}$ angular dependence of the amplitudes is parametrized by constant phase shifts and appropriate polynomial functions, conserving amplitude symmetries. The lack of observables at some angles is compensated by imposed smooth functions of angle which average possible anomalies in the angular dependences of observables.

The differential cross-section provides not only an absolute normalization at all angles, but, in addition, plays the same role as any other observable.

In energy-dependent PSA, the phase shifts are parametrized as functions of energy, as explained in $[21,37]$. This imposes to all parameters a relatively smooth energy dependence. That's why the PSA description alone is not an ideal tool for the study of possible resonances.

e unique all spinreal and ct of one $A$ by its no effect implitude maginary ted. The ect to the d cancels

id in the mplitudes utions of $90^{\circ}$ (c.m.) p) systems

$\therefore$ and PSA ck of PSA inalysis is

Assuming that the electromagnetic part of the nucleon-nucleon (NN) elastic scattering is well known, the PSA below the pion production threshold for a fixed isospin state $(I)$ is practically model independent. At these energies, the phase shifts are real, the unitarity of the scattering matrix is conserved and energy threshold conditions are simple. A weakly model-dependent part is introduced for the description of peripheral interaction above a given cut in the angular momentum. Usually one pion exchange (OPE) amplitudes are used to complete this lacking part. The OPE contribution also insures a stability of the PSA solutions, i.e. the low phase shifts change very little, if the angular momentum cut is changed.

Due to inelastic interactions, PSA become more model dependent with increasing energy. The inelasticity is reflected by imaginary parts of phase shifts with different thresholds. In principle, any phase shift may be complex, which increases the number of free parameters. The only observable usable in the PSA which is directly related to the imaginary parts of phase shifts is the total inelastic cross-section. The OPE contribution supplements only for real parts of phase shifts. The imaginary parts for large angular momenta must be taken from models. Moreover, for the np PSA it is necessary either to perform a common pp and np PSA, or tix the $I=1$ phases to values determined by the pp PSA. For all these reasons there exists an upper energy limit for the PSA method, which could be hardly estimated.

The best way of checking the validity of model-dependent contributions to PSA is to compare the PSA amplitude predictions with the direct reconstruction from the amplitude analysis. From this point of view, the amplitude analysis is to be considered as a complementary method with respect to the PSA. Agreement of the results will then support the PSA which may then be used to predict conveniently unmeasured quantities. A disagreement will either suggest a possible anomaly in the database, or will throw a doubt on the validity of the obtained PSA solutions.

Previous statements are valid also at low energy close to the pion production 
threshold. In this energy region, the amplitude analysis is equally important as it provides not only a check of the PSA, but mainly checks the validity of different potential models (not treated here, see [21]).

In ref. [37] were listed different phase shift analyses carried out before 1980 , when the necessary np database for spin-dependent observables above $0.8 \mathrm{GeV}$ was nonexistent. The development of this database is described in ref. [21]. In the present paper we compare the amplitude analysis results with the results of two PSA [10,20] containing almost the same data.

\section{4. - Data base and selection of solutions}

In the NN experimental program the beam was polarized along $\vec{k}, \vec{n}$, or $\vec{s}$, while the target was polarized along $\vec{k}$ or $\vec{n}$. The polarization components in $\vec{n}$ and/or $\vec{s}$ " directions of the recoil particles were analyzed. Small contributions of some "undesired" observables were suppressed by performing additional measurements. The beam polarization direction was flipped every burst of SATURNE II. Two modes of the longitudinal target polarization inversion were used in each relevant measurement: in the first one the sign of the intrinsic target polarization was changed, in the second the target holding field was rotated.

The observables (2.5), (2.8) to (2.11) were measured in a single scattering of the polarized neutron beam in the PPT. All other observables need an asymmetry measurement of the recoil protons. The statistics of the rescattering events is about $2 \%$ of that for single scattering and determines the accuracy of the amplitude analysis. The rescattering parameters $P_{\text {onoo }}$ and $N_{\text {onnn }}$ were not used in the calculations, since their accuracy is much lower than that of $A_{\text {oono }}$ and $A_{\text {ooon }}$. They were used to check the intrinsic compatibility of each experiment.

The elastic-scattering differential cross-section data, which were not measured in the NN program at SATURNE II, were taken from the VPI energy-dependent pp and np PSA up to $1.3 \mathrm{GeV}[10]$. At $\theta \geqslant 40^{\circ}$ above $0.8 \mathrm{GeV}$ up to $1.1 \mathrm{GeV}$, there exist only two $\mathrm{d} \sigma / \mathrm{d} \Omega(\mathrm{np})$ data sets [37,38]; at $0.991 \mathrm{GeV}$ from Birmingham [39], and at $1.028 \mathrm{GeV}$ from PPA [40]. The PPA data, measured in a large energy region, show different angular dependence at energies where other measurements exist. They were excluded from the majority of PSA's. However, the np database contain measurements at small angles [41], several sets at large angles above $\theta \geqslant 130^{\circ}$ [42], as well as total crosssections. Only the common pp and np energy-dependent PSA [10], including all other existing data, may predict a reasonable differential cross-section angular dependence in our energy region.

At $0.80 \mathrm{GeV}$ the PSA fits $[10,20]$ represent the best average over a large amount of existing $\mathrm{d} \sigma / \mathrm{d} \Omega(\mathrm{np})$ results from refs. [39, 41-45].

Relations (2.4) to $(2.18)$ and condition (2.19) were used to calculate the real and imaginary parts of amplitudes by a least-squares fit to data at angles where complete sets of observables exist. These angles are imposed by rescattering measurements. The complete sets are arailable in the forward hemisphere only. Since measurements were performed at slightly different angles, each observable was interpolated over a small angular vicinity.

The search for solutions started from random sets of amplitudes. If one solution was accepted, the procedure was repeated. Every new solution was accepted if it was different from the preceding ones within the errors. This search was repeated several

hundred 1 one solut

Some

amplitud. "trivial sı

Then

criterion.

solutions

The $\mathrm{f}$

The $\mathrm{r}$

depender cross-sec amplitud

It is obv and vice

The , reaches crosses

Re $a$ cro are non-

and

interval: angle.

Lool one $\theta$ w the sam two sea -1 , re: are non analyzi region

If a any ene provide conseq!

The monote fast de solution

The They n 
It as it ifferent

1. when

$\checkmark$ was ) resent $(10,20]$

, while

Vor $\vec{s} "$ some ments. modes levant anged,

of the imetry un $2 \%$ is. The their : $\mathrm{k}$ the

red in sp and ly two $8 \mathrm{GeV}$ ferent sluded small crossother dence unt of 1 and iplete $\therefore$ The were small 11 was was veral

hundred times until only previously accepted solutions appeared. In general, more than one solution was found in the majority of the searches.

Some solutions show either uncertainties of $\pm 180^{\circ}$ for relative phases of all amplitudes or give the amplitude $e$ identically equal to zero. These solutions, called "trivial solutions", were removed.

Then the remaining non-trivial solutions may be selected on the basis of a $\chi^{2}$ criterion, if the $\chi^{2}$ values per degree of freedom (DF) differ significantly. All trivial solutions always have large $\chi^{2}$ values.

The following criteria are "non-statistical" ones.

The most powerful criterion is based on the shape of the analyzing power angular dependence, which is well known. Multiplying $A_{\text {omo }}$ by the positive definite differential cross-section, we obtain the available experimental quantity expressed in terms of two amplitudes only (see eq. (2.8)). Using the condition (2.19), we can write

$$
\sigma A_{\text {oono }}=|a| e \cos \phi_{a} .
$$

It is obvious that for a fixed $\sigma A_{\text {omno }}$ value, a decrease of Re $a$ requires an increase of $e$ and vice versa.

The observable $A_{\text {oono }}(\mathrm{np})$ is equal to zero at $0^{\circ}$ and at $180^{\circ} \mathrm{cm}$. At our energies it reaches one broad maximum around $30^{\circ} \mathrm{c} . \mathrm{m}$. and a broad minimum at $\sim 110^{\circ} \mathrm{c}$ c.m. It crosses zero once, from positive towards negative values at $\sim 70^{\circ} \mathrm{c} . \mathrm{m}$. At this point Re $a$ crosses zero and the relative phase $\phi_{a}(\mathrm{np})= \pm 90^{\circ}$, whereas $|a(\mathrm{np})|$ and $e(\mathrm{np})$ are non-zero, in general. Both

$$
0^{\circ} \leqslant \phi_{a} \leqslant 180^{\circ}
$$

and

$$
180^{\circ} \leqslant \phi_{a} \leqslant 360^{\circ}
$$

intervals of the $\phi_{a}$ values are equally valid at one energy and at one single scattering angle.

Looking at an interval of scattering angles, considerations will be different. If at one $\theta$ we find the phase $\phi_{a}(\mathrm{np})$ in one of the intervals (4.2) and at a neighbouring angle the same phase passes in the other interval, it is obvious that somewhere between these two scattering angles $\phi_{a}$ crosses either $0^{\circ}$, or $180^{\circ}$. At this point $\cos \phi_{a}$ is either 1 , or -1 , respectively, and $A_{\text {oono }}(\mathrm{np})$ reaches a local extremum (we assume that $|a|$ and $e$ are non-zero). No such feature has been observed in the angular dependence of the np analyzing power. From this there follows that any $\phi_{a}$ value over our scattering angular region can vary inside one and only one of either intervals (4.2).

If a unique solution was obtained in the amplitude analysis in our angular range at any energy, $\phi_{a}$ value was always found in the interval (4.2a). The PSA procedure also provides $\phi_{a}$ values in the same interval. Taking this fact into account, we have consequently removed all solutions with $\phi_{a}$ in the interval $(4.2 b)$.

The solutions selected by the previous rule gave large positive values of $\operatorname{Im} b$, monotonically decreasing from $20^{\circ} \mathrm{c} . \mathrm{m}$. to $80^{\circ} \mathrm{c} . \mathrm{m}$. in our energy region. This rather fast decrease may also be used as another criterion to remove some of the multiple solutions.

The respective absolute values of amplitudes $b, c$, and $d$ are always well determined. They may differ only a little for all solutions at any fixed angle. Combining eqs. (2.4) to 
(2.7), we obtain

TABLE I.

number i

$$
\begin{aligned}
& |b|^{2}=\frac{1}{2} \sigma\left(1+D_{\text {onon }}-K_{\text {onno }}-A_{\text {oomn }}\right), \\
& |c|^{2}=\frac{1}{2} \sigma\left(1-D_{\text {onon }}+K_{\text {onno }}-A_{\text {oonn }}\right), \\
& |d|^{2}=\frac{1}{2} \sigma\left(1-D_{\text {onon }}-K_{\text {omno }}+A_{\text {oonn }}\right) .
\end{aligned}
$$

Amplitude $(\sqrt{\mathrm{mb} / \mathrm{sr}}$

Re $a$ Ima $\operatorname{Re} b$ $\operatorname{Im} b$ $\operatorname{Re} c$ $\operatorname{Im} c$

All three observables were measured and introduced in the amplitude analyses at all energies. A large difference of absolute values (4.3) to (4.5) for one of the solutions is an indication for its rejection. The amplitude $b$ is one of the dominant ones and $|b|$ will be more accurately determined than $|c|$ and $|d|$, which are small in our angular region.

Similar relations for $|a|^{2}$ and $|e|^{2}$ contain another observable with four spin indices [35], which is practically impossible to measure. This observable cancels in a simple relation for the sum

$$
|a|^{2}+|e|^{2}=\frac{1}{2} \sigma\left(1+D_{\text {onon }}+K_{\text {onno }}+A_{\text {oonn }}\right) .
$$

This sum alone represents a weak criterion. On the other hand, eq. (4.6) together with eq. (4.1) strongly relate $|a|^{2}$, and then $\operatorname{Im} a$, with the well measured analyzing power. We may expect a good determination of $\operatorname{Im} a$.

The amplitude $e$ is equal to zero in the forward direction and reaches a maximum between $30^{\circ}$ and $40^{\circ} \mathrm{c.m}$., where $A_{\text {oono }}$ has a large maximum. This maximum moves towards smaller angles with increasing energy.

Finally, the solutions indicating very large statistical uncertainties, namely for real and imaginary parts of the dominant amplitudes $(a, b$, and $e)$, may be removed. Such solutions are special cases of trivial solutions.

In the figures we compare the PSA predictions $[10,20]$ with the results of the amplitude analyses. Both PSA predictions are in good agreement in the angular region of the amplitude analysis at any energy.

The errors of amplitudes represent the square roots of the diagonal error matrix elements.

\section{5. - Results and discussion}

The selected solutions differ in $\chi^{2}$ values only a little. The $\chi^{2} / \mathrm{DF}$ are given in tables. The probability of a given solution is often independent of the frequency of its repetition by a search from random initial parameters.

The solutions of analyses are presented by the real and imaginary parts of amplitudes and not by their absolute values and relative phases. Small values of some real or imaginary parts, even determined with a convenient absolute accuracy, may provide important fluctuations of corresponding relative phase angular distributions. Nevertheless, the relative phases are useful for the selection of solutions.

Fig. 1. imagina! predictio ref. $[20]$. 
TABLE I. - Results at $0.80 \mathrm{GeV}$. The ratios of $\chi^{2} / \mathrm{DF}$ are given in brackets after the solution number in all tables.

\begin{tabular}{lrr}
\hline $\begin{array}{l}\text { Amplitude } \\
(\sqrt{\mathrm{mb} / \mathrm{sr}})\end{array}$ & $\begin{array}{l}\theta=48.2^{\circ} \\
\text { Sol. } 1(0.81)\end{array}$ & \multicolumn{1}{c}{$\begin{array}{l}\theta=61.7^{\circ} \\
\text { Sol. } 1(0.81)\end{array}$} \\
\hline $\operatorname{Re} a$ & $0.617 \pm 0.087$ & $0.234 \pm 0.019$ \\
$\operatorname{Im} a$ & $0.634 \pm 0.338$ & $0.384 \pm 0.247$ \\
$\operatorname{Re} b$ & $0.049 \pm 0.309$ & $0.040 \pm 0.298$ \\
$\operatorname{Im} b$ & $1.721 \pm 0.059$ & $1.175 \pm 0.031$ \\
$\operatorname{Re} c$ & $-0.234 \pm 0.239$ & $-0.017 \pm 0.182$ \\
$\operatorname{Im} c$ & $0.036 \pm 0.074$ & $0.052 \pm 0.029$ \\
$\operatorname{Re} d$ & $-0.527 \pm 0.145$ & $-0.106 \pm 0.132$ \\
$\operatorname{Im} d$ & $0.188 \pm 0.066$ & $0.025 \pm 0.037$ \\
$\operatorname{Re} e$ & $1.501 \pm 0.208$ & $1.160 \pm 0.090$ \\
\hline
\end{tabular}

vses at all olutions is id $|b|$ will ir angular

four spin ncels in a

ether with ng power.

maximum im moves ly for real ved. Such Its of the iar region or matrix in tables. icy of its

parts of ss of some lacy, may cributions.



Fig. 1. - The direct reconstruction of $\mathrm{np}$ elastic scattering amplitudes at $0.80 \mathrm{GeV}$. Real and imaginary parts of amplitudes (black dots) are given in $\sqrt{\mathrm{mb} / \mathrm{sr}}$. Solid curves represent the predictions of the VPI PSA [10], the dashed curves are calculated by the Saclay-Geneva PSA of ref. [20]. All existing np data points are introduced in both analyses at all energies. 
Using the rules discussed above, we give the results for each of the six energies. Since the solutions at one angle are independent of the solutions at any other one, the notation of solutions is arbitrary. For instance, Sol. 1 at $\theta_{x}$ is not necessarily related with Sol. 1 at $\theta_{y}$.

the inter Saclay-Ge

5b) Enerk

\section{5a) Energy $0.80 \mathrm{GeV}$}

The amplitude analysis was performed at $48.2^{\circ} \mathrm{c.m}$. and $61.7^{\circ} \mathrm{c} . \mathrm{m}$. Two solutions at each angle were obtained; only one was accepted. The omitted solution has $\phi_{a}$ in

TABLE II. - Results at $0.84 \mathrm{GeV}$.

The a:

At the rejected : either for

At 61 . was omitt

\begin{tabular}{|c|c|c|c|}
\hline $\begin{array}{l}\text { Amplitude } \\
(\sqrt{\mathrm{mb} / \mathrm{sr}})\end{array}$ & $\begin{array}{l}\theta=53.5^{\circ} \\
\text { Sol. } 1(0.97)\end{array}$ & $\begin{array}{l}\theta=53.5^{\circ} \\
\text { Sol. } 2(0.97)\end{array}$ & $\begin{array}{l}\theta=53.5^{\circ} \\
\text { Sol. } 3(0.97)\end{array}$ \\
\hline $\begin{array}{l}\operatorname{Re} a \\
\operatorname{Im} a \\
\operatorname{Re} b \\
\operatorname{Im} b \\
\operatorname{Re} c \\
\operatorname{Im} c \\
\operatorname{Re} d \\
\operatorname{Im} d \\
\operatorname{Re} e\end{array}$ & $\begin{array}{r}0.516 \pm 0.080 \\
0.776 \pm 0.295 \\
-0.497 \pm 0.315 \\
1.275 \pm 0.136 \\
0.434 \pm 0.251 \\
-0.274 \pm 0.275 \\
-0.475 \pm 0.258 \\
-0.309 \pm 0.204 \\
1.156 \pm 0.179\end{array}$ & $\begin{array}{r}0.603 \pm 0.092 \\
0.947 \pm 0.105 \\
1.151 \pm 0.237 \\
0.726 \pm 0.329 \\
-0.414 \pm 0.260 \\
-0.340 \pm 0.285 \\
-0.187 \pm 0.212 \\
-0.497 \pm 0.178 \\
1.991 \pm 0.150\end{array}$ & $\begin{aligned} 0.491 & \pm 0.080 \\
0.739 & \pm 0.207 \\
1.286 & \pm 0.134 \\
0.477 & \pm 0.307 \\
0.480 & \pm 0.221 \\
-0.267 & \pm 0.263 \\
-0.312 & \pm 0.212 \\
0.402 & \pm 0.204 \\
1.215 & \pm 0.194\end{aligned}$ \\
\hline $\begin{array}{l}\text { Amplitude } \\
(\sqrt{\mathrm{mb} / \mathrm{sr}})\end{array}$ & $\begin{array}{l}\theta=61.5^{\circ} \\
\text { Sol. } 1(0.24)\end{array}$ & $\begin{array}{l}\theta=61.4^{\circ} \\
\text { Sol. } 2(0.61)\end{array}$ & $\begin{array}{l}\theta=61.4^{\circ} \\
\text { Sol. } 3(0.36)\end{array}$ \\
\hline $\begin{array}{l}\operatorname{Re} a \\
\operatorname{Im} a \\
\operatorname{Re} b \\
\operatorname{Im} b \\
\operatorname{Re} c \\
\operatorname{Im} c \\
\operatorname{Re} d \\
\operatorname{Im} d \\
\operatorname{Re} e\end{array}$ & $\begin{array}{r}0.206 \pm 0.018 \\
0.324 \pm 0.414 \\
0.591 \pm 0.414 \\
0.910 \pm 0.279 \\
0.105 \pm 0.335 \\
0.295 \pm 0.136 \\
-0.049 \pm 0.159 \\
0.257 \pm 0.131 \\
1.216 \pm 0.084\end{array}$ & $\begin{array}{r}0.318 \pm 0.180 \\
0.947 \pm 0.254 \\
1.002 \pm 0.119 \\
0.366 \pm 0.254 \\
-0.317 \pm 0.233 \\
0.192 \pm 0.270 \\
0.110 \pm 0.212 \\
-0.248 \pm 0.142 \\
1.789 \pm 0.443\end{array}$ & $\begin{aligned} 0.262 & \pm 0.113 \\
0.753 & \pm 0.485 \\
-0.712 & \pm 0.149 \\
0.818 & \pm 0.122 \\
0.230 & \pm 0.163 \\
0.210 & \pm 0.152 \\
-0.371 & \pm 0.104 \\
0.027 & \pm 0.172 \\
1.961 & \pm 0.411\end{aligned}$ \\
\hline $\begin{array}{l}\text { Amplitude } \\
(\sqrt{\mathrm{mb} / \mathrm{sr}})\end{array}$ & $\begin{array}{l}\theta=74.1^{\circ} \\
\text { Sol. } 1(0.77)\end{array}$ & $\begin{array}{l}\theta=74.1^{\circ} \\
\text { Sol. } 2(0.99)\end{array}$ & \\
\hline $\begin{array}{l}\operatorname{Re} a \\
\operatorname{Im} a \\
\operatorname{Re} b \\
\operatorname{Im} b \\
\operatorname{Re} c \\
\operatorname{Im} c \\
\operatorname{Re} d \\
\operatorname{Im} d \\
\operatorname{Re} e\end{array}$ & $\begin{aligned} 0.003 & \pm 0.017 \\
0.663 & \pm 0.242 \\
-0.406 & \pm 0.139 \\
0.648 & \pm 0.092 \\
0.063 & \pm 0.138 \\
0.217 & \pm 0.085 \\
-0.387 & \pm 0.093 \\
-0.014 & \pm 0.048 \\
0.532 & \pm 0.297\end{aligned}$ & $\begin{array}{r}0.002 \pm 0.011 \\
0.279 \pm 0.139 \\
0.203 \pm 0.427 \\
0.684 \pm 0.125 \\
-0.336 \pm 0.117 \\
0.131 \pm 0.127 \\
0.285 \pm 0.118 \\
-0.117 \pm 0.187 \\
0.834 \pm 0.063\end{array}$ & \\
\hline
\end{tabular}

Fig. 2. - 7 circles anc same as it 
nergies. 'ne, the related

olutions is $\phi_{a}$ in

$i=0.134$

$\pm 0.307$

$1 \pm 0.221$

$\pm 0.263$

$: \pm 0.212$

$\therefore \pm 0.204$

$i \pm 0.194$

$t^{\circ}$

$0.36)$

$: \pm 0.113$

$: \pm 0.485$

$\therefore \pm 0.149$

$i \pm 0.122$

$1 \pm 0.163$

$1 \pm 0.152$

$1 \pm 0.104$

$i \pm 0.172$

$1 \pm 0.411$ the interval (4.2b). (see table I and fig. 1 together with the VPI PSA[10] and the Saclay-Geneva PSA [20]).

\section{5b) Energy $0.84 \mathrm{GeV}$}

The amplitude analysis was performed at $53.5^{\circ}, 61.4^{\circ}$, and $74.1^{\circ} \mathrm{c} . \mathrm{m}$.

At the smallest angle seven solutions were found, three of them were accepted. Two rejected solutions have $\phi_{a}$ in $(4.2 b)$, and all of the omitted ones have very large errors either for $\operatorname{Re} a$ and/or for $\operatorname{Im} b$.

At $61.4^{\circ}$ four solutions were obtained and three were accepted. The fourth solution was omitted due to $\phi_{a}$ in $(4.2 b)$.

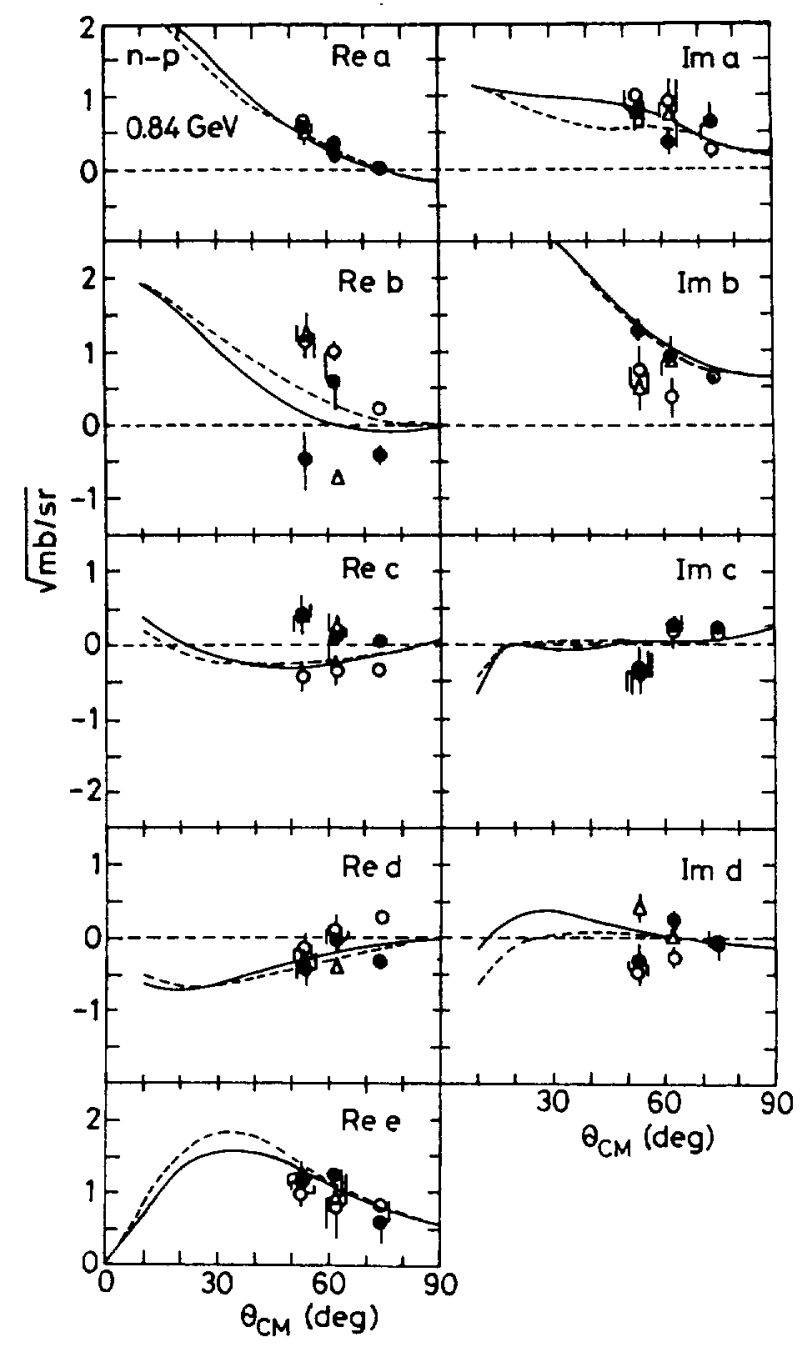

Fig. 2. - The direct reconstruction of $n$ p scattering amplitudes at $0.84 \mathrm{GeV}$. The black dots, open circles and triangles represent results for different solutions in the tables. Other symbols are the same as in fig. 1 . 
Two solutions were found at $74.1^{\circ}$ and both were accepted.

The results are given in table $I I$ and are shown in fig. 2. We observe a good agreement of $\operatorname{Re} a$, Im $c$, and $e$ with both PSA. Several solutions differ from PSA predictions for $\operatorname{Re} b$ and $\operatorname{Im} b$.

\section{5c) Energy $0.88 \mathrm{GeV}$}

The amplitudes were reconstructed at $49.4^{\circ}, 55.9^{\circ}, 60.8^{\circ}$, and $77.2^{\circ} \mathrm{c} . \mathrm{m}$.

At the smallest angle six solutions were found and two were accepted. Two of the

TABLE III. - Results at $0.88 \mathrm{GeV}$.

\begin{tabular}{|c|c|c|c|c|}
\hline $\begin{array}{l}\text { Amplitude } \\
(\sqrt{\mathrm{mb} / \mathrm{sr}})\end{array}$ & $\begin{array}{l}\theta=49.4^{\circ} \\
\text { Sol. } 1(0.42)\end{array}$ & $\begin{array}{l}\theta=49.4^{\circ} \\
\text { Sol. } 2(1.22)\end{array}$ & $\begin{array}{l}\theta=55.9^{\circ} \\
\text { Sol. } 1(1.35)\end{array}$ & $\begin{array}{l}\theta=55.9^{\circ} \\
\text { Sol. } 2(1.50)\end{array}$ \\
\hline $\operatorname{Re} a$ & $0.539 \pm 0.053$ & $0.644 \pm 0.070$ & $0.355 \pm 0.034$ & $0.366 \pm 0.031$ \\
\hline $\operatorname{Im} a$ & $0.598 \pm 0.266$ & $0.828 \pm 0.091$ & $0.489 \pm 0.277$ & $0.599 \pm 0.149$ \\
\hline $\operatorname{Re} b$ & $0.229 \pm 0.457$ & $1.319 \pm 0.190$ & $-0.017 \pm 0.457$ & $0.967 \pm 0.237$ \\
\hline $\operatorname{Im} b$ & $1.428 \pm 0.098$ & $0.687 \pm 0.347$ & $1.259 \pm 0.034$ & $0.760 \pm 0.297$ \\
\hline $\operatorname{Re} c$ & $-0.640 \pm 0.158$ & $0.482 \pm 0.176$ & $-0.203 \pm 0.227$ & $0.360 \pm 0.113$ \\
\hline $\operatorname{Im} c$ & $-0.237 \pm 0.246$ & $0.322 \pm 0.255$ & $-0.107 \pm 0.144$ & $0.000 \pm 0.137$ \\
\hline $\operatorname{Re} d$ & $-0.501 \pm 0.109$ & $-0.036 \pm 0.170$ & $-0.422 \pm 0.093$ & $-0.188 \pm 0.142$ \\
\hline $\operatorname{Im} d$ & $-0.111 \pm 0.137$ & $0.720 \pm 0.089$ & $0.012 \pm 0.100$ & $0.339 \pm 0.101$ \\
\hline $\operatorname{Re} e$ & $1.464 \pm 0.137$ & $1.193 \pm 0.119$ & $1.286 \pm 0.120$ & $1.245 \pm 0.100$ \\
\hline Amplitude & $\theta=60.8^{\circ}$ & $\theta=60.8^{\circ}$ & $\theta=60.8^{\circ}$ & \\
\hline$(\sqrt{\mathrm{mb} / \mathrm{sr}})$ & Sol. $1(1.24)$ & Sol. $2(0.79)$ & Sol. $3(0.85)$ & \\
\hline $\operatorname{Re} a$ & $0.236 \pm 0.026$ & $0.238 \pm 0.034$ & $0.293 \pm 0.041$ & \\
\hline $\operatorname{Im} a$ & $0.262 \pm 0.548$ & $0.278 \pm 0.635$ & $0.718 \pm 0.142$ & \\
\hline $\operatorname{Re} b$ & $-0.530 \pm 0.559$ & $-0.315=0.886$ & $0.848 \pm 0.149$ & \\
\hline $\operatorname{Im} b$ & $0.902 \pm 0.341$ & $0.999 \pm 0.286$ & $0.607 \pm 0.204$ & \\
\hline $\operatorname{Re} c$ & $-0.314 \pm 0.101$ & $0.318 \pm 0.095$ & $0.337 \pm 0.087$ & \\
\hline $\operatorname{Im} c$ & $0.086 \pm 0.103$ & $-0.022 \pm 0.092$ & $0.053 \pm 0.121$ & \\
\hline Red & $0.365 \pm 0.117$ & $-0.385 \pm 0.113$ & $-0.275 \pm 0.090$ & \\
\hline $\operatorname{Im} d$ & $0.135 \pm 0.170$ & $-0.128 \pm 0.268$ & $0.268 \pm 0.070$ & \\
\hline $\operatorname{Re} e$ & $1.170 \pm 0.123$ & $1.161 \pm 0.161$ & $0.945 \pm 0.127$ & \\
\hline Amplitude & $\theta=77.2^{\circ}$ & $\theta=77.2^{\circ}$ & & \\
\hline$(\sqrt{\mathrm{mb} / \mathrm{sr}})$ & Sol. $1(0.29)$ & Sol. $2(0.25)$ & & \\
\hline $\operatorname{Re} a$ & $-0.050 \pm 0.006$ & $-0.051 \pm 0.008$ & & \\
\hline $\operatorname{Im} a$ & $0.102 \pm 0.275$ & $0.164 \pm 0.343$ & & \\
\hline $\operatorname{Re} b$ & $0.446 \pm 0.213$ & $-0.530 \pm 0.175$ & & \\
\hline $\operatorname{Im} b$ & $0.526 \pm 0.177$ & $0.441 \pm 0.206$ & & \\
\hline $\operatorname{Re} c$ & $0.205 \pm 0.050$ & $-0.206 \pm 0.049$ & & \\
\hline $\operatorname{Im} c$ & $0.041 \pm 0.045$ & $0.034 \pm 0.045$ & & \\
\hline $\operatorname{Re} d$ & $0.080 \pm 0.081$ & $-0.097 \pm 0.067$ & & \\
\hline $\operatorname{Im} d$ & $-0.096 \pm 0.047$ & $-0.087 \pm 0.052$ & & \\
\hline $\operatorname{Re} e$ & $1.768 \pm 0.042$ & $0.757 \pm 0.076$ & & \\
\hline
\end{tabular}

rejected

large er

At 5

omitted

same al

Ten

errors were or

At

solution (35.7\%

The amplitu
Fig. 3 as in $f$ 
ive a good from PSA

Two of the rejected solutions have $\phi_{a}$ in the interval $(4.2 b)$, and all the omitted ones have very large errors either for $\operatorname{Re} a, b$, or for $\operatorname{Im} a, b$.

At $55.9^{\circ}$ eight solutions were obtained and two were accepted. Three solutions were omitted due to $\phi_{n}$. In the other three omitted solutions, large errors appear in the same amplitudes.

Ten solutions were found at $60.8^{\circ}$ and three were accepted. The Sol. 3 gives small errors in all amplitudes and its frequency of repetition is only $2.5 \%$. Four solutions were omitted due to $\phi_{a}$ and the remaining ones were omitted due to large errors.

At $77.2^{\circ}$ three solutions were obtained and two were accepted. The accepted solutions differ only in $\operatorname{Re} b$ and $\operatorname{Re} c$. The third solution, which is the most frequent (35.7\% of searches), was omitted due to very large errors in Re $a$ and in $e$.

The results are given in table III and are shown in fig. 3 . $\operatorname{Re} b$ and $\operatorname{Im} b$ for some amplitude analysis solution differ from the both PSA predictions.



Fig. 3. - The direct reconstruction of pp scattering amplitudes at $0.88 \mathrm{GeV}$. Symbols are the same as in figs. 1 and 2. 
TABLE IV. - Results at $0.94 \mathrm{GeV}$.

\begin{tabular}{|c|c|c|c|}
\hline $\begin{array}{l}\text { Amplitude } \\
(\sqrt{\mathrm{mb} / \mathrm{sr}})\end{array}$ & $\begin{array}{l}\theta=46.7^{\circ} \\
\text { Sol. } 1(0.74)\end{array}$ & $\begin{array}{l}\theta=53.8^{\circ} \\
\text { Sol. } 1(0.36)\end{array}$ & $\begin{array}{l}\theta=58.7^{\circ} \\
\text { Sol. } 1(1.82)\end{array}$ \\
\hline $\operatorname{Re} a$ & $0.776 \pm 0.454$ & $0.369 \pm 0.067$ & $0.254 \pm 0.024$ \\
\hline $\operatorname{Im} a$ & $1.164 \pm 0.484$ & $0.489 \pm 0.698$ & $0.454 \pm 0.232$ \\
\hline $\operatorname{Re} b$ & $-0.576 \pm 0.333$ & $-0.466 \pm 0.851$ & $0.188 \pm 0.873$ \\
\hline $\operatorname{Im} b$ & $1.503 \pm 0.125$ & $1.155 \pm 0.345$ & $0.978 \pm 0.174$ \\
\hline $\operatorname{Re} c$ & $-0.042 \pm 0.403$ & $-0.317 \pm 0.245$ & $-0.439 \pm 0.127$ \\
\hline $\operatorname{Im} c$ & $-0.217 \pm 0.349$ & $0.001 \pm 0.276$ & $0.037 \pm 0.217$ \\
\hline $\operatorname{Re} d$ & $-0.454 \pm 0.218$ & $-0.101 \pm 0.311$ & $0.248 \pm 0.218$ \\
\hline $\operatorname{Im} d$ & $0.031 \pm 0.320$ & $-0.095 \pm 0.176$ & $-0.048 \pm 0.227$ \\
\hline $\operatorname{Re} e$ & $1.185 \pm 0.695$ & $1.408 \pm 0.250$ & $1.192 \pm 0.099$ \\
\hline $\begin{array}{l}\text { Amplitude } \\
(\sqrt{\mathrm{mb} / \mathrm{sr}})\end{array}$ & $\begin{array}{l}\theta=72.1^{\circ} \\
\text { Sol. } 1(0.53)\end{array}$ & $\begin{array}{l}\theta=72.1^{\circ} \\
\text { Sol. } 2(0.89)\end{array}$ & \\
\hline $\operatorname{Re} a$ & $-0.002 \pm 0.010$ & $-0.002 \pm 0.011$ & \\
\hline $\operatorname{Im} a$ & $0.344 \pm 0.257$ & $0.407 \pm 0.236$ & \\
\hline $\operatorname{Re} b$ & $-0.054 \pm 0.229$ & $0.401 \pm 0.183$ & \\
\hline $\operatorname{Im} b$ & $0.645 \pm 0.044$ & $0.495 \pm 0.144$ & \\
\hline $\operatorname{Re} c$ & $-0.272 \pm 0.127$ & $-0.283 \pm 0.136$ & \\
\hline $\operatorname{Im} c$ & $0.185 \pm 0.150$ & $0.206 \pm 0.164$ & \\
\hline $\operatorname{Re} d$ & $-0.275 \pm 0.076$ & $0.219 \pm 0.121$ & \\
\hline $\operatorname{Im} d$ & $0.032 \pm 0.121$ & $-0.146 \pm 0.150$ & \\
\hline $\operatorname{Re} e$ & $0.747 \pm 0.126$ & $0.719 \pm 0.135$ & \\
\hline
\end{tabular}

\section{5d) Energy $0.94 \mathrm{GeV}$}

The amplitudes are given at $46.7^{\circ}, 53.8^{\circ}, 58.7^{\circ}$, and $72.1^{\circ} \mathrm{c.m}$.

At the smallest angle two solutions were found and one was accepted. The second solution was omitted due to the undetermined $\operatorname{Im} b$ and the very large errors of $\operatorname{Re} a$.

At $53.8^{\circ}$ the solution is unique.

Two solutions were found at $58.7^{\circ}$ and one was accepted. The omitted solution has the dominant frequency of repetition $(75.3 \%)$, but the majority of the amplitudes remained undetermined.

At $72.1^{\circ}$ three solutions were obtained and two were accepted. The accepted solutions differ only in Re $d$. The third solution was omitted due to $\phi_{a}$ in the interval (4.2b). The results are given in table IV and are shown in fig. 4.

\section{5e) Energy $1.00 \mathrm{GeV}$}

The amplitude analyses were carried out at $47.3^{\circ}, 56.1^{\circ}, 62.3^{\circ}$, and $77.1^{\circ} \mathrm{c} . \mathrm{m}$.

At the smallest angle two solutions were found and two were accepted. The first solution, which was the most frequent $(66.7 \%$ of searches), is shown, but it has large errors in $\operatorname{Re} a$ and $e$ and may be omitted. 


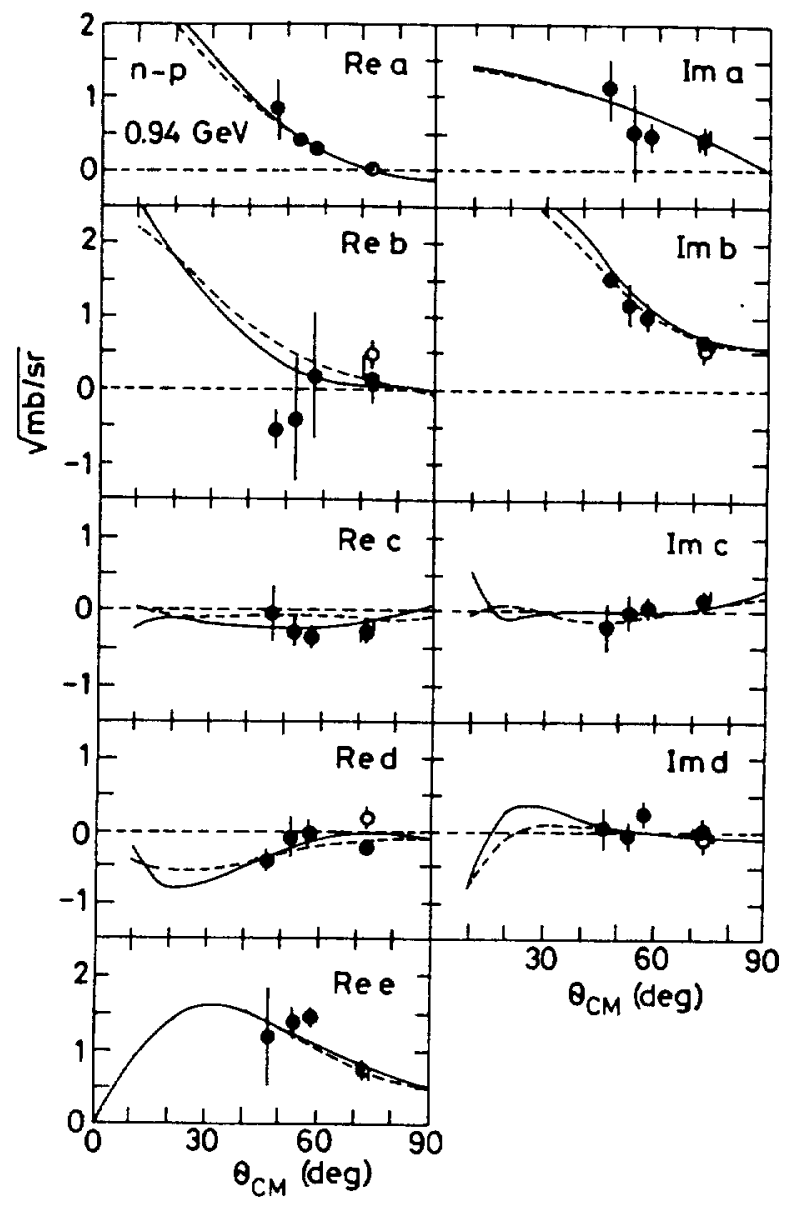

Fig. 4. - The direct reconstruction of pp scattering amplitudes at $0.94 \mathrm{GeV}$. Symbols are the same as in figs. 1 and 2.

At $56.1^{\circ}$ three solutions were obtained and two were accepted. The second solution may be, in principle, omitted due to large errors in Re $a$ and in $e$. The third solution was omitted due to $\phi_{a}$ in $(4.2 b)$.

Three solutions were found at $62.3^{\circ}$ and one was accepted. This solution is also the most frequent (75.4\% of searches). One solution was omitted due to $\phi_{a}$ in $(4.2 b)$; another one, less frequent, was removed due to very large errors in $\operatorname{Re} a, \operatorname{Im} a$, and Re $b$.

At $77.1^{\circ}$ two solutions were obtained and only one can be accepted. The omitted solution has $\phi_{a}$ in $(4.2 b)$. The results are given in table $\mathrm{V}$ and are shown in fig. 5 .

\section{5f) Energy $1.10 \mathrm{GeV}$}

At this energy, which is close to the highest neutron energy at SATURNE II, the amplitude analyses were carried out at $3 \mathrm{c} . \mathrm{m}$. angles: $42.3^{\circ}, 53.1^{\circ}$, and $68.0^{\circ} \mathrm{c.m}$.

At $42.3^{\circ}$ a unique solution exists. We present this solution although the errors of the 
TABLE V. - Results at $1.00 \mathrm{GeV}$.

\begin{tabular}{|c|c|c|c|c|}
\hline $\begin{array}{l}\text { Amplitude } \\
(\sqrt{\mathrm{mb} / \mathrm{sr}})\end{array}$ & $\begin{array}{l}\theta=47.3^{\circ} \\
\text { Sol. } 1(0.66)\end{array}$ & $\begin{array}{l}\theta=47.3^{\circ} \\
\text { Sol. } 2(0.86)\end{array}$ & $\begin{array}{l}\theta=56.1^{\circ} \\
\text { Sol. } 1(1.05)\end{array}$ & $\begin{array}{l}\theta=56.1^{\circ} \\
\text { Sol. } 2(1.39)\end{array}$ \\
\hline $\begin{array}{l}\operatorname{Re} a \\
\operatorname{Im} a \\
\operatorname{Re} b \\
\operatorname{Im} b \\
\operatorname{Re} c \\
\operatorname{Im} c \\
\operatorname{Re} d \\
\operatorname{Im} d \\
\operatorname{Re} e\end{array}$ & $\begin{array}{r}0.963 \pm 0.481 \\
1.072 \pm 0.117 \\
0.367 \pm 0.577 \\
1.386 \pm 0.179 \\
-0.376 \pm 0.286 \\
0.380 \pm 0.197 \\
-0.334 \pm 0.077 \\
0.498 \pm 0.201 \\
0.932 \pm 0.463\end{array}$ & $\begin{array}{r}0.629 \pm 0.090 \\
0.813 \pm 0.264 \\
0.522 \pm 0.562 \\
1.325 \pm 0.248 \\
-0.585 \pm 0.187 \\
-0.056 \pm 0.282 \\
-0.416 \pm 0.131 \\
-0.067 \pm 0.198 \\
1.427 \pm 0.198\end{array}$ & $\begin{array}{r}0.352 \pm 0.038 \\
0.528 \pm 0.239 \\
0.124 \pm 0.559 \\
1.073 \pm 0.094 \\
-0.139 \pm 0.358 \\
-0.189 \pm 0.196 \\
-0.475 \pm 0.155 \\
-0.086 \pm 0.148 \\
1.152 \pm 0.118\end{array}$ & $\begin{array}{r}0.455 \pm 0.192 \\
0.831 \pm 0.322 \\
0.980 \pm 0.153 \\
0.456 \pm 0.271 \\
0.212 \pm 0.295 \\
-0.084 \pm 0.219 \\
-0.429 \pm 0.112 \\
0.250 \pm 0.206 \\
0.911 \pm 0.390\end{array}$ \\
\hline $\begin{array}{l}\text { Amplitude } \\
(\sqrt{\mathrm{mb} / \mathrm{sr}})\end{array}$ & $\begin{array}{l}\theta=62.3^{\circ} \\
\text { Sol. } 1(0.18)\end{array}$ & $\begin{array}{l}\theta=77.1^{\circ} \\
\text { Sol. } 2(1.06)\end{array}$ & & \\
\hline $\begin{array}{l}\operatorname{Re} a \\
\operatorname{Im} a \\
\operatorname{Re} b \\
\operatorname{Im} b \\
\operatorname{Re} c \\
\operatorname{Im} c \\
\operatorname{Re} d \\
\operatorname{Im} d \\
\operatorname{Re} e\end{array}$ & $\begin{array}{r}0.224 \pm 0.098 \\
0.728 \pm 0.254 \\
0.773 \pm 0.085 \\
0.367 \pm 0.156 \\
0.192 \pm 0.161 \\
-0.173 \pm 0.134 \\
-0.481 \pm 0.094 \\
0.116 \pm 0.130 \\
0.688 \pm 0.298\end{array}$ & $\begin{array}{r}-0.082 \pm 0.012 \\
0.086 \pm 0.114 \\
0.075 \pm 0.429 \\
0.567 \pm 0.067 \\
-0.290 \pm 0.118 \\
0.144 \pm 0.101 \\
0.084 \pm 0.137 \\
-0.061 \pm 0.154 \\
0.651 \pm 0.037\end{array}$ & & \\
\hline
\end{tabular}

amplitudes are large. At $53.1^{\circ}$ two solutions were obtained and both were accepted. Only one solution was found at $68.0^{\circ}$. The results are given in table VI, where the values of $|b|$ are also listed (see next subsection). The amplitudes are plotted in fig. 6 .

\section{$5 g$ ) Amplitude $b$ )}

At several energies we observe a fluctuation of the present results for this amplitude. This effect is stronger for $\operatorname{Re} b$. Equation (4.3) explains why $|b|$ is well determined. This is demonstrated in table VI where, in addition, we listed the $|b|$ values at all angles. Consequently, $\phi_{b}$ is poorly determined, which indicates a lack of accurate data determining the amplitude $\operatorname{Re} b$ or $\operatorname{Im} b$ in the amplitude analysis as well as in the PSA. Such a combination of observables is, for instance,

$$
\sigma\left(A_{o o s s}+A_{\text {corkk }}\right)=2 \operatorname{Re} b^{*} c
$$

from eqs. (2.9) and (2.10). The observable $A_{\text {ouss }}$ was measured at LAMPF $[16,18]$ and was introduced in the amplitude analysis at $0.80 \mathrm{GeV}$ only. The parameter $A_{\text {sxikk }}$ has been accurately measured at all energies, but is small in the present angular range. The relative phase $\phi_{b}$ is mainly determined by a combination of two dominant terms in eq. (2.12) for the observable $D_{o w^{\prime \prime}(k)}$. Unfortunately, this rescattering observable,

Fig. 5. as in fig

reachir the sit best $\mathrm{ch}$

Table

Amplitu: $(\sqrt{\mathrm{mb} / \mathrm{s}}$ Re $a$ $\operatorname{lm} a$ Reb $\operatorname{Im} b$ $|b|$ Rec Ime Red Ind Rer 
:39)

epted. re the ted in

$r$ this $\therefore$ well ie $|b|$ ack of is well

i] and $i k$ has range. terms vable,

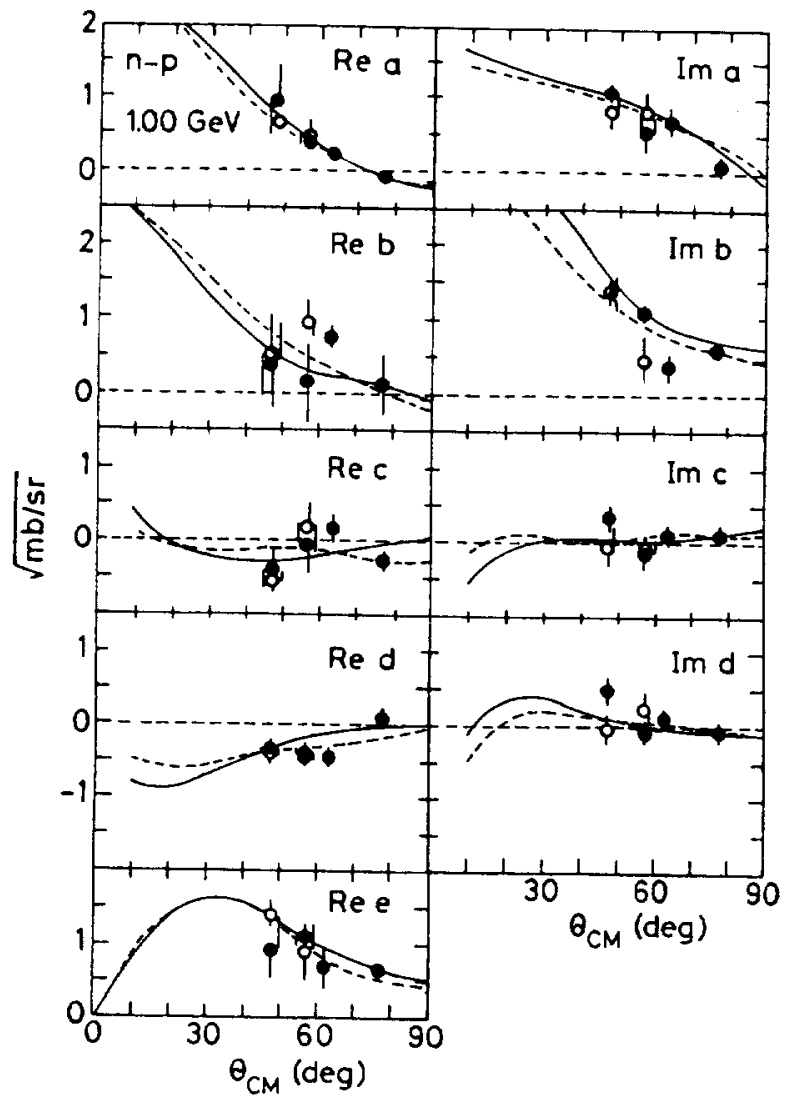

Fig. 5. - The direct reconstruction of pp scattering amplitudes at $1.00 \mathrm{GeV}$. Symbols are the same as in figs. 1 and 2 .

reaching large values, could not be measured with a sufficient accuracy [8]. To improve the situation, a measurement of the single scattering observable $A_{\text {ooss }}$ represents the best choice.

TABLE VI. - Results at $1.10 \mathrm{GeV}$.

\begin{tabular}{|c|c|c|c|c|}
\hline $\begin{array}{l}\text { Amplitude } \\
(\sqrt{\mathrm{mb} / \mathrm{sr}})\end{array}$ & $\begin{array}{l}\theta=42.3^{\circ} \\
\text { Sol. } 1(1.52)\end{array}$ & $\begin{array}{l}\theta=53.1^{\circ} \\
\text { Sol. } 1(0.74)\end{array}$ & $\begin{array}{l}\theta=53.1^{\circ} \\
\text { Sol. } 2(1.16)\end{array}$ & $\begin{array}{l}\theta=68.0^{\circ} \\
\text { Sol. } 1(0.42)\end{array}$ \\
\hline $\operatorname{Re} a$ & $1.172 \pm 1.001$ & $0.821 \pm 0.562$ & $0.517 \pm 0.183$ & $0.060 \pm 0.023$ \\
\hline $\operatorname{Im} a$ & $1.072 \pm 0.215$ & $0.832 \pm 0.260$ & $0.835 \pm 0.306$ & $0.292 \pm 0.234$ \\
\hline $\operatorname{Re} b$ & $0.612 \pm 0.686$ & $1.051 \pm 0.367$ & $0.776 \pm 0.611$ & $-0.362 \pm 0.406$ \\
\hline $\operatorname{Im} b$ & $1.627 \pm 0.359$ & $0.571 \pm 0.620$ & $0.875 \pm 0.548$ & $0.607 \pm 0.223$ \\
\hline$|b|$ & $1.738 \pm 0.098$ & $1.196 \pm 0.042$ & $1.170 \pm 0.059$ & $0.706 \pm 0.035$ \\
\hline $\operatorname{Re} c$ & $-0.425 \pm 0.484$ & $0.229 \pm 0.205$ & $-0.356 \pm 0.187$ & $0.046 \pm 0.340$ \\
\hline $\operatorname{Im} c$ & $0.295 \pm 0.434$ & $0.068 \pm 0.270$ & $0.042 \pm 0.267$ & $-0.149 \pm 0.121$ \\
\hline $\operatorname{Re} d$ & $-0.294 \pm 0.116$ & $-0.226 \pm 0.117$ & $-0.065 \pm 0.183$ & $0.240 \pm 0.196$ \\
\hline Im d & $0.344 \pm 0.501$ & $0.432 \pm 0.158$ & $-0.138 \pm 0.201$ & $-0.132 \pm 0.193$ \\
\hline $\operatorname{Re} e^{\prime}$ & $1.116 \pm 0.951$ & $0.6332 \pm 0.431$ & $1.004 \pm 0.352$ & $0.713 \pm 0.11: 3$ \\
\hline
\end{tabular}




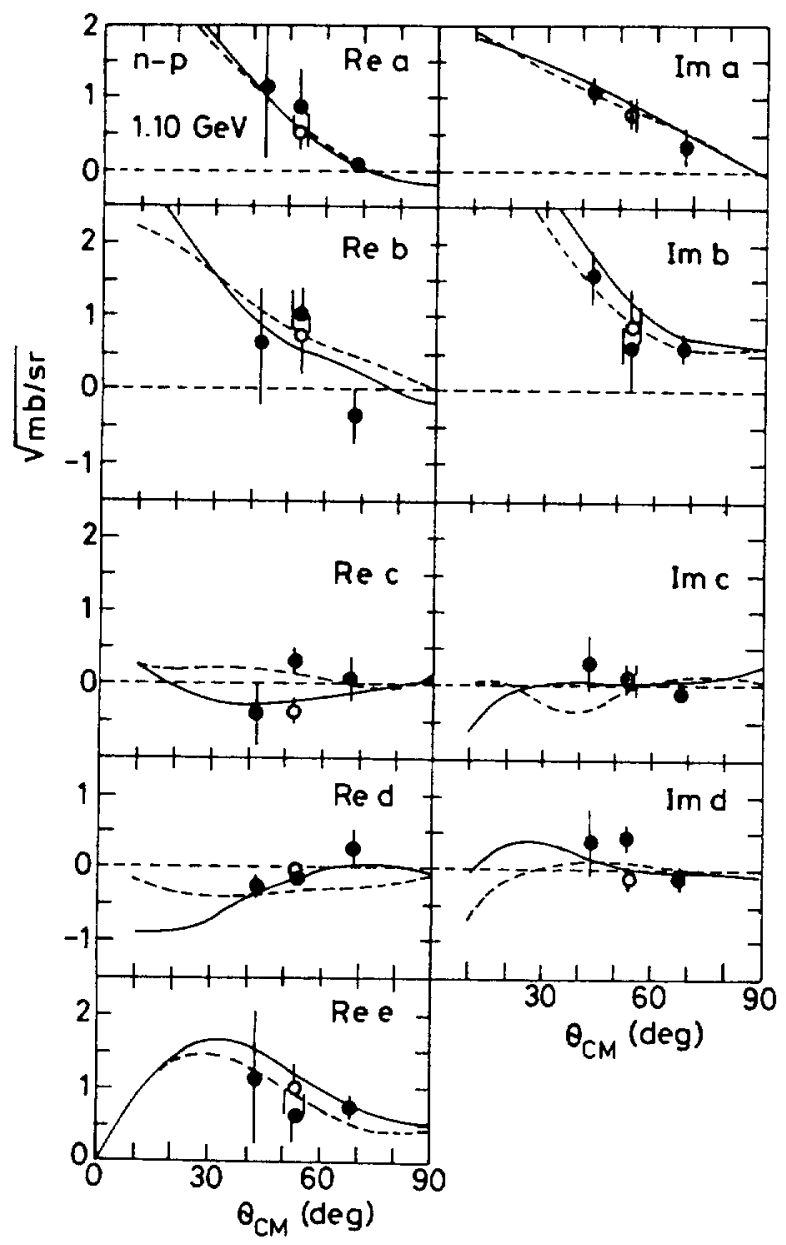

obse

to th

relat

need.

$\mathrm{T}$

recol

u

base

some

II. T

Nuclt

Foun

REF

Fig. 6. - The direct reconstruction of pp scattering amplitudes at $1.10 \mathrm{GeV}$. Symbols are the same as in figs. 1 and 2.

\section{6. - Conclusions}

The np elastic-scattering amplitude analysis was performed using complete sets of observables at six neutron energies from 0.80 to $1.10 \mathrm{GeV}$ at several angles. The spin-dependent experiments at the five high energies were measured at SATURNE II during the period from 1986 to 1991. At these energies, the differential cross sections from the PSA fit to all existing data points were used. At $0.80 \mathrm{GeV}$ the data base was completed using the LAMPF data.

Selection rules for multiple amplitude solutions were described and applied to the results obtained. In general, one to three solutions remained. The results are listed in tables and are plotted in figures. They show a smooth angular dependence of amplitudes at all energies. They were compared with the amplitudes calculated by two PSA, involving full sets of measurements. For the majority of the solutions, a good agreement of the present results and PSA predictions wals found. The fluctuations, 
observed in the present results and in the PSA predictions for the ampliturle $b$. are due to the small values of certain observables. These observables contribute mainly to the relative phase $\phi_{l}$, whereas $|b|$ is well determined. New measurements, such as $A_{t u \times x}$, needed for further improvements, were suggested.

This amplitude analysis of $n p \rightarrow n p$ data represents the first existing direct reconstruction of the $n p$ scattering matrix.

We thank I. I. StRakovsky and P. WinTernitz for comments concerning the data base and the method used. We express our gratitude to all physicists participating in some activity relevant to the np part of the Nucleon-Nucleon program at SATURNE II. This work was supported in part by the U.S. Department of Energy, Division of Nuclear Physics, Contract No. W-31-109-ENG-38 and by Swiss National Science Foundation.

\section{REFERENCES}

[1] Puzikov L. D., Ryvdin R. M. and Smorodinskir YA. A., Nucl. Phys., 3 (195i) 436.

[2] Bystricky J., Lehar F., Patera J. and Winternitz P., Lect. Notes Phys., 87 (1978) 509.

[3] Ball J., Chesny Ph., Combet M., Fontaine J.-M., Kuvine R., Lemaire M. C., Savs J. L., Bystricky J., Lac C. D., Lehar F., de Lesqlen A., de Mali M., Perrot-Kunve F., Van Rossum L., Bach P., Demierre Ph., Gaillard G., Hess R., Rapin D., Sorma.yi Ph., Goldolr J. P., Binz R., KletT A., Rössle E., SchuitT H., Barabash L. S., Janolt Z., Khachatlrov B. A., Usov Yu. A., Lopiano D. and SpINka H., Nucl. Phys. A, 559 (1993) 477.

[4] Ball J., Chesny Ph., Combet M., Fontaine J.-M., Lac. C.D, Sans J. L.. Bystricky J., Lehar F., de Lesqlen A., de Mali M., Perrot-Kline F., va. Rosscm L., Ahmidolch A., Bach P., Demierre Ph., Gall lard G., Hess R., Kunve R., Rafin D., Sorma.ii Ph., Goldol'r J. P., Binz R., Klett A., Rössle E., Schuitt H., Lopiano D. and Spinka H., Vucl. Phys. A, 559 (1993) 489.

[5] Ball J., Cyesny Ph., Conbet M., Fontaine J.-M., Lac C. D., Lemaire M. C., Saxs J. L., Bystricky J., Lehar F., de Lesquen A., de Mali M., Perrot-Kl.Nee F., van Rosscy L., Bach P., Demierre Ph., Galllard G., Hess R., Klinde R., Rapin D., Sorma.ii Ph., Goldolre J. P., Binz R., KLETt A., Rössle E., Schyitr H., Barabash L. S., Javolt Z., Khachatlrov B. A., Usov Yl. A., Lopiavo D. and SpINka H., Nucl. Phys. A, 559 (1993) 511: Erratum, Nucl. Phy.s. A, 576 (1994) 640.

[6] Ball J., Lac C. D., Lehar F., de Lesqlen A., van Rosich L., Chacmette P., Derégel J., Fabre J., de Mali M., Fontaine J.-M., Perrot F., Bach P., Gaillard G., Hess R., RapiN D., Surmani Ph., Ghazkhasiali V., Whittex C. A., Peschisa R. and Rössle E., Z. Phys. C. 40 (1988) 193.

e sets of

les. The

RNE II sections hase was

d to the listed in dence of al by two $\therefore$ a good tuations,

[7] Ball. J., Chesiy Ph., Conbet M., Fontaine J.-M., Lae C.D., Sans J. L., Bistrichy .J., Lehar F., de Lesqlex A., de Mali M., Perrot-Kinge F., van Rosscu L., Bach P., Demerere Ph., Galllatid G., Hess R., Kenve R., Rapix D., Surmani Ph.. Goldolr J. P., BiN. R., Klett A., Peshina-Ki.ett R., Rössi.e E. and Schmitt H., Nucl. Ph!js. A, 574 (1994) (6)

[8] Bal., J., Chesny Ph., Combet M., Fontarnf, J.-M., Kinge R., Lematre M. C., Saxs .J. L.,

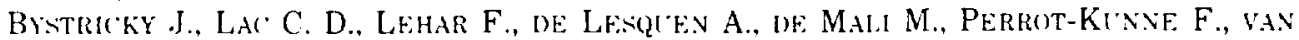

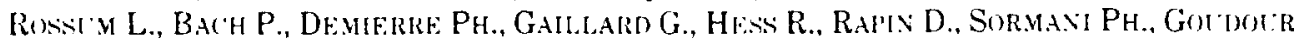

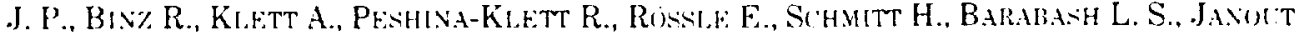

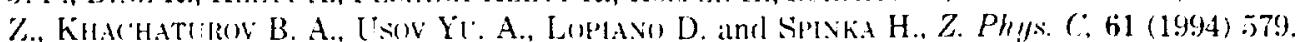

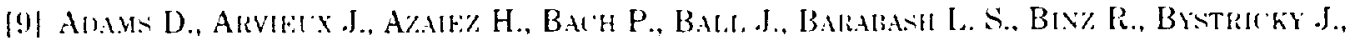

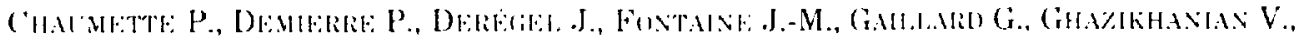


Gordon J., Hasegana T., Hess R., Javolt Z., Khachat 'rov B. A., Klett A., Kl:Ne R., Lac C.D., Lehar F., Lemaike M.C., de Lesquen A., Lopiayo D., de Mal, M., A. Michalowicz, C. R. Newsom C. R., Y. Onel, A. Penzo, F. Perrot-Kline F., Peschina-Klett R., Rapin D., Raymond C., Rösle E., van Rossim L., Schmitt H., Sans J. L., Sormani P., Spinka H., Usov Yl. A., Vearidel B. and WhitTen C. A., Acta Polytech. (Prague), 36 (1996) 11.

[10] Arndt R. A, Strakovsky I. I. and Workman R. L., Phys. Rev. C, 50 (1994) 2731 (SAID, program, solution FA95).

[11] Barlett M. L., Hoffmaix G. W., McGill J. A., Hoistad B., Ray L., Fergerson R. W., Milner E. C., Marshall J. A., Amann J. F., Bonner B. E., McClelland J. B., Blanpied G. S. and Arndt R. A., Phys. Rev. C, 27 (1983) 682.

[12] MCNalghton M. W., Koch K., Supek I., Tanaka N., McNalghton K. H., Riley P. J., Ambrose D. A., Johnson J. D., Smith A., Glass G., Hiebert J. C., Northcliffe L. C, SimoN A. J., Adams D. L., Ransome R. D., Clayton D. B., Spinka H. M., Jeppesex R. H. and Tripard G. E., Phys. Rev. C, 44 (1991) 2267.

[13] McNalghton M. W., Johnston K., Swenson D. R., Tupa D., York R. L., Ambrose D. A., Coffey P., McNalghton K. H, Riley P. J., Glass G., Hiebert J. C., Jeppesen R. H., Spinka H., Slpek I., Tripard G. E. and Woolverton H., Phys. Rev. C, 48 (1993) 256.

[14] McNalghton M. W., McNaughton K. H., Glass G., Riley P. J., Auer K. H., Davis C. A., Gülmez E., Hiebert J. C., Jeppesen R. H., Raisome R. D., Spinka H., Sum V., Supek I., Tripard G. E. and Woolverton H., Phys. Rev. C, 53 (1996) 1092.

[15] Nath S., Glass G., Hiebert J. C., Holt J. A., Kenefick R. A., Northcliffe L. C., Grosnick D. P., Lopiano D., Ohashi Y., Shima T., Spinka H. M., Stanek R., Bhatia T. S., Jarmer J. J., Riley P. J., Sen S., Faucett J. A., Kyle G., Jeppesen R. H. and Tripard G. E., Phys. Rer: D, 39 (1989) 3520.

[16] Shima T., Hill D., Johnson K. F., Shimizu H., Spinka H., Stanek R., Underwood D., Yokosawa A., Glass G., Hiebert J. C., Kenefick R. A., Nath S., Northcliffe L. C., Blrleson G. R., Garnett R. W., Faucett J. A., Rawool-Sullivan M. W., Damjanovich R., Jarmer J. J., Jeppesen R. H. and Tripard G. E., Phys. Rev. D, 47 (1993) 29.

[17] Ditzler W. R., Hill D., Hoftiezer J., Johnson K.F., Lopiano D., Shima T., Shimizu H., Spinka H., Stanek R., Underwood D., Wagner R.G., Yokosawa A., Burleson G. R., Faucett J. A., Fontenla C. A., Garnett R. W., Llichini C., Rawool-Sullivan M. W., Bhatia T. S., Glass G., Hiebert J. C., Kenefick J. A., Nath S., Northcliffe L. C., Damjanovich R., Jarmer J. J., Vaninetti J., Jeppesen R. H. and Tripard G. E., Phys. Rev. D, 46 (1992) 2792.

[18] Carlson V., Garnett R., Hill D., Johnson K. F., Lopiano D., Ohashi Y.. Shima T., Spinka H., Stanek R., Underwood D., Yokosawa A., Beddo M., Burleson G., Falicett J. A., Kyle G., Rayool-Silliyan M., Shimizl H., Glass G., Nath S., Northcliffe L. C., Jakmer J. J., Jeppesex R. H. and G. E. Tripard G. E., Phys. Rev. D, 53 (1996) 3506.

[19] Glass G., Bhatia T. S., Hiebent J. C., Kenefick R. A., Nath S., Nonthlliffe. L. C., Johnsox K. F., Spinka H., Stanek R., Rawool. M. W., Falcett J. A., Jeppesex R. H., Tripari G. E. and Newsom C. R., Phys. Reu C. 41 (1990) 2732.

[20] Brsthicky J., Lechanoine-Leluc C. and Lehak F., J. Phys. France, 51 (1990) 2747 (1997 solutions above $0.8 \mathrm{GeV}$ ).

[21] Lechanoine-LeLic C. and Lehar F., Rec. Mod. Phys., 65 (1993) 47.

[22] Fontainf. J.-M., E.rperientia Suphl., 25 (1975) 464.

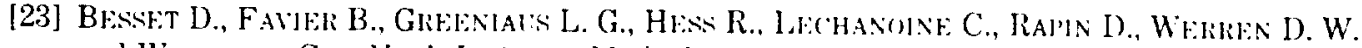
and Weim)like Ch., Nucl. Instrmm. Methods, 14s (1978) 129).

[24] Hal:ammani R., PhD Thesis No. 2038, DPNC, Lniversity of Geneva, 195'?

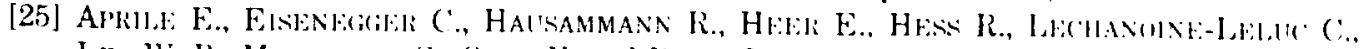

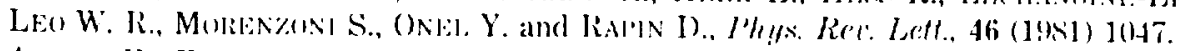

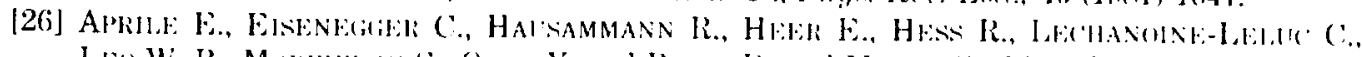

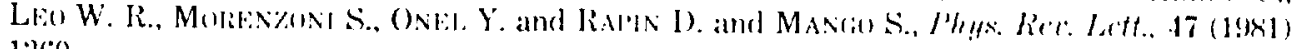
1360.

[27] $\mathrm{M} \times \mathbf{N}$ J., Gi

[28] ALAS:

[29] $\mathrm{LAC}($ FoNT

[30] AIEI: SANU: A. ani

[31] LEHA Bonn

[32] BALL

[33] AHMI D., $\mathrm{Tr}$ S., Sc DREN Inter" Amstr JAGEI Amst

[34] PART1 Labor

[35] Bysti

[36] KLEP 505.

[37] BrST: Elasti. Kaon (Sprin

[38] Bistl Karls,

[39] MLRE 49 (19)

[40] SHEP.A

[41] Siliei KHAN: Niucl.

[42] BizaI: Di'Fl.

[43] CaRLI Aleki R.. II Univel

[44] Evit:Boxil DIETI: $497: 1$ article

|45| JA1X ? botis D)1:TH: 
INWE: R., LAC HICHALOWIC\%, T"T R., RapIN S. Sinka H. I!) 11. 2731 (SAID, MAN R. W., Blavpled G.

RILEY P. J., L. C, SIMON $\therefore$ R. H. and

BRosE D. A., WE.N R. H., (3) 256 .

Davis C. A., V., SLPEK I.,

IFFE L. C., iHATIA T. S., Tripard G.

ERWOOD D., IFFE L. C. IANOVICH R.

Shimize $H$. , FNON G. R., WAN M. W. IFFE L. C., . Phys. Rev.

I T., SplnkA J. A., KYLE IRMER J. J.

IFFE L. C., SEN R. H.

$.2747(1997$

IRREN D. W.

-Latac C., 47.

-Leflec C. 1., 47 (1981)



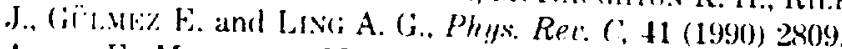



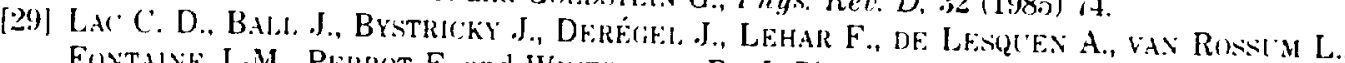
Fontaine .J.-M., Perrot F. and Winternitz P.. J. Phys. (France), 51 (1990) 2689.

[30] Alerk I. P., Chalmeks J., Culton E., Giese R., Halperiy H., Hill. D., Miller R., Nield K. Sandter B., Splnka H., Tavera N., Underwood D., Watavabe Y., Yokosawa A., Beretvas A. and Mille. D., Phys. Rev. D, 32 (1985) 1609.

[31] LEHAR F., Proceedings of the 9th International Symposium on High Energy Spin-Physics, Borm 1990, edited by K.-H. ALTHOFF and W. MEYER, Vol. 1 (Springer-Verlag) 1991. p. 113

[32] Ball. J., PhD thesis, Université de Paris-Sud, Orsay, No. 2132

[33] Ahmidouch A., Demierre Ph., Goujon-Naef N., Hess R., Lechanolne-Lelle C., Rapis D., Teglia A., Vuaridel B., van den Brandt B., Daum M., Haltle P., Konter J. A., Mavino S., Schmelzbach P. A., Arnold J., Franz J., Lacker H., Rössle E., Schmitt H., Sereni P. Drevenik R., Finger M., Finger M. jr., JandTa A., SluneČk M. and Lehar F., 12th International Symposium on High Energy Spin Physics, September 10-1\%, 1996, Amsterdam, The Netherlands, SPIN 96 Proceedings (World Scientific), edited by C. W. DE Jager, T. J. Ketel, P. J. MLlders, J. E. J. Oberski and M. Oskam-Tamboezer (NIKHEF, Amsterdam), p. 588.

[34] Particle Data Grolp (UK), University of Durham, Department of Physics Science Laboratories, South Road, Durham, DH1 3LE, England.

[35] Bystricky J., Lehar F. and Winternitz P., J. Phys. (Paris), 39 (1978) 1 [36] KLEPIKov N. P., Ż. Éksp. Teor. Fiz., 47 (1964) 757; Sov.Phys. JETP (Engl. Transl.), 20 (1965)
505.

[37] Bystricky J., Carlson P., Lechanoine C., Lehar F., Mönvig F. and Schlbert K. R. Elastic and Charge Exchange Scattering of Elementary Particles a: Nucleon Nucleon and Kaon Nucleon Scattering - Landolt-Börnstein, New Series, edited by H. SCHOPPER, Vol. 9 (Springer-Verlag, Berlin, Heidelberg, New York) 1980

[38] BYSTRICKY J. and LEHAR F., Nucleon-Nucleon Scattering Data, Fachinformationszentrum Karlsruhe, edited by H. BEHRE.ss und G. EBEL, Nr. 11-1 (1978), Nr. 11-2 and 11-3 (1981).

[39] Murray T. A., Riddiford L., Grayer G. H., Jones T. W. and TANimlira Y., Nuovo Cimento, 49 (1967) 261.

[40] Shepard P. F., Devlin T. J., Mischke R. E. and Solomon J., Phys. Rev. D, 10 (1974) 2735.

[41] Silverman B. H., Lugol J. C., Saudinos J., Terrien Y., Wellers F., Dobrovolshy A. V., Khanzadeev A. V., Korolev G. A., Petrov G. E., Spiridenkov E. M. and Vorobyov A. A., Nucl. Phys A, 499 (1989) 763.

[42] Bizard G., Bonthonneal F., Laville J. L., Lefébvres F., Malherbe J. C., Regimbart R., Dlflo J. and Plouin F., Nucl. Phys. B, 85 (1975) 14.

[43] Carlini R., Dieterle B., Donahue J., Leavitt C., Rupp T., Thomas W., Wolfe D., Auerbach L. B., Highland V. L., Johnson K. F., McFarlane W. K., Pratt J. and Bentley R., Phys. Rev. Lett., 41 (1978) 1341 (Numerical table given in CaRLiNi R.. PhD thesis, University of New Mexico, Albuquerque, 1977).

[44] Evais M. L., Glass G., Hiebert J. C., Jain M., Kenefick R. A., Northcliffe L. C., Bunner B. E., Simmons J. E., Buork C. W., Rheey P. J., Bryant H. C., Casiapakis C. G., Dieterle B., LeavitT C. P., Wolfe D. M. and Werren D. W., Phys. Rev. Lett, 36 (1976) 497; Phys. Rev. C, 26 (1982) 2525 (Numerical table can be found in [38], but also in the second article listed above).

[45] Jaln M., Evans M. L., Glass G., Hiebert J. C., Kenefick R. A., Northlifffel L. C., Bonner B. E., Simmons J. E., B.jork C. W., Rulfy P. J., Bryant H. C. Cassapakts C. G. Dieterle: B., Leavitt C. P., Wolfe D. M. and Werlik. D. W., Phys. Rov. C. 30 (1984) j66. 
